\title{
6p22 microdeletion syndrome
}

INSERM

\section{Source}

INSERM. (1999). Orphanet: an online rare disease and orphan drug data base. 6 p22

microdeletion syndrome. ORPHA:251046

$6 p 22$ microdeletion syndrome is a newly described syndrome associated with a variable clinical phenotype including developmental delay, facial dysmorphism, short neck and diverse malformations. 